\title{
IMPLEMENTAÇÃO DE UMA CULTURA LEAN MANUFACTURING NO SETOR DE EQUIPAMENTOS DE GERAÇÃO DE ENERGIA: UMA ANÁLISE COMPARATIVA ENTRE A TEORIA E A PRÁTICA
}

\section{IMPLEMENTATION OF A LEAN MANUFACTURING CULTURE IN AN ENERGY GENERATION EQUIPMENTS' MANUFACTURING: COMPARATIVE ANALYSIS BETWEEN THEORY AND PRACTICE}

\author{
Guilherme Escarabelin Molinero ${ }^{1^{*}}$ \& Manoel Gonçales Filho ${ }^{2}$ \\ ${ }^{12}$ Universidade de São Paulo, Escola Superior de Agricultura Luiz de Queiroz (PECEGE) \\ ${ }^{* 1}$ gui.molinero@gmail.com ${ }^{2}$ manoel.goncales01@ fatec.sp.gov.br
}

\section{ARTIGO INFO.}

Recebido em: 04.10.2021

Aprovado em: 10.11.2021

Disponibilizado em: 01.02.2022

Palavras-Chave:

Lean; Energia; Produção.

KEYWORDS:

Lean; Energy; Production.

*Autor Correspondente: Molinero, G. E.

\section{RESUMO}

Lean manufacturing é uma das principais filosofias aplicadas para aumento de produtividade devido ao grande sucesso da Toyota e subsequentemente grande expansão pela indústria automotiva. Esta cultura de melhoria continua tem sido estudada por diversos autores e decomposta em passos de uma metodologia para implementação e controle, entretanto diversos estudos apontam uma taxa de insucesso bastante elevada na replicação do lean. Nesse contexto, o objetivo deste estudo foi a implementação da filosofia lean no setor de fabricação de componentes para geração de energia renovável, a fim de comparar os desafios da implementação e os processos executados com a literatura clássica sobre o assunto. A metodologia de estudo foi aplicada através de estudo de caso com coleta de dados por meio de entrevistas semiestruturadas para um grupo de especialistas de uma empresa no setor de energias renováveis, sendo também comparativa com a literatura de lean. Com o resultado, foram constatados três processos principais constituintes da implementação do lean neste setor: Hoshin Kanri, Mapeamento do fluxo de valor e eventos Kaizen. Em seguida foram comparados com a literatura para identificar diferenças e a partir desta comparação foram elaboradas sugestões de melhorias para a implementação destes três processos na empresa em estudo.

\begin{abstract}
Lean Manufacturing is one of the main applied philosophies to increase productivity due to Toyota's great success and further expansion to the automotive industry. This continuous improvement culture has been studied by several authors and decomposed into steps and methodologies to implement and control, however several studies point to an elevated failure rate on lean replication. In this context, the objective was to study the implementation of a lean manufacturing culture into renewable energy component's manufacturing. The study method was applied through a case study with data collection based on semi-structured interviews in a group of specialists from a company in the renewable energy sector, also being comparative to the lean manufacturing literature. Based on results, was understood tree main processes that constitutes the lean manufacturing implementation in this sector: Hoshin Kanri, Value Stream Mapping and Kaizen events. Results were compared with the literature to identify differences and based on the comparison, improvement suggestions were developed for the implementation of these tree processes in the studied company.
\end{abstract}



de geração de energia: uma análise comparativa entre a teoria e a prática. Brazilian Journal of Production Engineering, 8(1), 18-32.

\section{Introdução}

A manufatura enxuta - lean manufacturing, cunhado por James Womack e Daniel Jones na década de 1980, ganhou maior notoriedade por meio de seus estudos no Massachusetts Institute of Technology (MIT). Entretanto, a origem do lean manufacturing remonta o Sistema Toyota de Produção (STP) - Toyota Production System (TPS) iniciado na década de 1950 como forma de reduzir custos, aumentar a qualidade e velocidade. O lean é descrito como à busca para eliminação de desperdícios, ou seja, o que não tem valor para o cliente (Werkema, 2012).

Durante décadas o lean manufacturing foi aplicado e adaptado para diversos setores como uma forma de trabalho com ferramentas e métodos. Todavia, algumas indústrias não tiveram sucesso em sua implementação (Paro, 2016). O autor menciona estudos que reforçam uma taxa menor que $10 \%$ de sucesso em empresas do Reino Unido com base em uma pesquisa com 100 organizações. A pesquisa do autor apresenta como causas principais do insucesso na implementação lean, à cultura organizacional e a gestão de mudanças.

O lean manufacturing demonstra características de uma filosofia e não apenas processos e ferramentas que podem ser facilmente replicados, sendo que o modelo Toyota praticado por algumas empresas não têm funcionado e que a cultura organizacional e a gestão de mudanças apresentam-se como estruturas importantes na implementação de uma cultura lean manufacturing (Rother, 2010).

De acordo com Callefi (2020), a utilização de uma ferramenta gerencial através do lean manufacturing não parece ser suficiente para realizar grandes mudanças de pensamento, interpretações e comportamentos dos envolvidos na organização, uma vez que mudanças desse tamanho são decorrentes de um fenômeno mais amplo de práticas relacionadas aos processos gerenciais e técnicos, dessa forma, a mudança só poderá acontecer quando todos compreenderem a filosofia lean.

Pires e Macêdo (2006) consideram que a cultura é um padrão coletivo das maneiras de perceber, pensar, sentir e agir, bem como dos conjuntos de regras, hábitos e artefatos compartilhados pelo mesmo grupo social. Sendo assim, compreender a cultura é compreender o contexto em que as pessoas estão inseridas e possivelmente antever suas maneiras de agir.

Ainda assim alguns conceitos e ferramentas lean essenciais favorecem a implementação da filosofia, sendo: (i) Quatro pilares do STP; (ii) 14 princípios do Lean; (iii) Kanban; (iv) Produção puxada. Os quatro pilares do STP (Sistema Toyota de Produção) são: (i) Estabilidade; (ii) Padronização; (iii) Just in time e; (iv) Jidoka (Autonomação) (Liker, 2005).

Os 14 princípios lean são: (i) Baseiar decisões em uma filosofia de longo prazo mesmo em detrimento de metas financeiras de curto prazo; (ii) Criar um fluxo de processos para trazer problemas à tona; (iii) Utilizar sistemas puxados; (iv) Nivelar a carga de trabalho; (v) Promover a autonomação e cultura de qualidade; (vi) Padronizar tarefas; (vii) Usar o controle visual para verificar problemas; (viii) Usar somente tecnologia testada; (ix) Desenvolver líderes que vivenciam a filosofia; (x) Respeitar, desenvolver e desafiar as pessoas; (xi) Respeitar desafiar e auxiliar os fornecedores; (xii) Ver por si mesmo; (xiii) Tomar decisões 
lentamente, através do consenso. Implementá-las com rapidez e; (xiv) Aprendizagem organizacional contínua (Kaizen) (Liker, 2005).

Logo nos primeiros passos do desenvolvimento dos princípios lean pode ser encontrado o Hoshin kanri, ou planejamento hoshin. Este é um processo de curto prazo (um ano) e de longo prazo (de três a cinco anos) usado para identificar e tratar as necessidades administrativas mais cruciais, bem como desenvolver competências, alcançado ao alinhar os recursos da empresa em todos os níveis e ao ampliar o ciclo PDCA para atingir continuamente resultados esperados (Dennis, 2008). Hoshin significa "bússola" e Kanri significa "planejamento", sendo assim este termo consiste no processo de estabelecer objetivos, metas e os planos para seu atingimento (Liker \& Jones, 2013).

O Kanban originalmente era usado para cortar custos e gerenciar a utilização das máquinas. Hoje a Toyota usa o Kanban para identificar gargalos e alcançar a melhoria contínua. Desenvolvido por Taiichi Onho no final dos anos 1940 e início dos anos 1950, é uma ferramenta chave para a manufatura Just in time (JIT). Com o Kanban, os produtos são produzidos apenas para substituir os bens consumidos pelos clientes ou para responder aos sinais que seus clientes estão enviando (Gross \& McInnis, 2003). O processo produtivo sob demanda puxada define que nada deve ser produzido a menos que seja requisitado pelo cliente final, sendo a melhor forma de entender essa lógica e desafio seja começar a analisar o processo de trás para frente (Womack \& Jones, 2003).

O mapeamento do fluxo de valor (MFV) mostra a ligação entre o fluxo de informações e o fluxo de materiais, sendo que este mapa permite que se identifique todos os processos no chão de fábrica de porta a porta, ou seja, desde o fornecedor até o cliente final, ajudando a enxergar o fluxo e destacar as fontes de desperdício (Rother \& Shook, 2013).

O kaizen é a chave da qualidade e excelência de classe mundial da Toyota e define o modo com que a Toyota e aborda os negócios. Kaizen não é apenas um conjunto de ferramentas, mas o compromisso de se esforçar para melhorar continuamente, de forma que a melhoria contínua requer aprendizado contínuo e um ambiente que aceite mudanças (Liker, 2003). Os eventos Kaizen reúnem os trabalhadores para resolver problemas, podendos ser reuniões rápidas para simples soluções, como gerenciamento visual em uma estação de trabalho, ou para problemas maiores ou sistêmicos. Os trabalhadores devem possuir as habilidades para contribuir através de ideias ou resolução de problemas (Dennis, 2008).

Nesse sentido, tem-se uma problemática, uma questão a ser respondida e, tendo em conta as contribuições levantadas na literatura sob o tema principal desta pesquisa e a oportunidade de uma investigação à campo, definiu-se a questão norteadora desta pesquisa: Como implementar uma cultura lean manufacturing no setor de fabricação de componentes para geração de energia renovável. O objetivo que irá atender a questão de pesquisa está em: Realizar estudo de caso com responsáveis pela implementação da filosofia lean manufacturing no setor de fabricação de componentes para geração de energia renovável, visando apontar os desafios à implementação e identificar quais os processos foram utilizados. Os resultados serão comparados à conhecimentos difundidos pela literatura clássica relacionada ao lean manufacturing e às práticas da empresa em estudo. 


\section{Material e Métodos}

Pesquisas científicas iniciam-se com uma questão e objetivos de pesquisa, que podem resultar de experiências do próprio pesquisador ou de achados na literatura, e trazer contribuições ao campo do conhecimento (Gabriel, 2014). O conhecimento científico diferencia-se de outros conhecimentos por utilizar-se de levantamentos e análises metódicas e sistemáticas, sempre bem estruturadas, e que podem ser verificadas e comprovadas (Raupp e Beuren, 2008; Gerhardt e Souza, 2009; Zanella, 2011).

Neste capítulo é descrito o aspecto metodológico adotado na pesquisa, quanto à̀ classificação geral, natureza, métodos de pesquisa, objetivos de pesquisa, procedimento técnico, técnica de coleta e análise dos dados e a caracterização da empresa investigada - unidade de análise e amostra.

A pesquisa conduzida foi de natureza aplicada com o objetivo de gerar conhecimentos para aplicação prática de solução de problemas específicos (Gerhardt \& Souza, 2009). Foi adotado o método comparativo nesta pesquisa, consistindo em investigar fatos e explicá-los com base em semelhanças e diferenças (Fachin, 2006).

Sob o ponto de vista de seus objetivos foi exploratória e buscou detalhar o problema para construir proposições. Na maioria dos casos, essas pesquisas envolvem um levantamento bibliográfico, entrevistas com pessoas que possuam experiências no problema pesquisa e análise de casos ou exemplos. Desta forma, foi também bibliográfica com base, principalmente, em livros e artigos científicos. Por fim, foi explicativa, pois visa identificar fatores importantes para a ocorrência do assunto pesquisado (Gil, 2002).

O levantamento bibliográfico foi realizado nas bases de dados do (i) Google Acadêmico; (ii) Portal de Periódicos da CAPES; (iii) Banco de pesquisas acadêmicas do Pecege USP / ESALQ; (iv) Biblioteca Digital de Teses e Dissertações da USP, por meio das palavras-chave: (i) Lean Manufacturing; (ii) Melhoria contínua e; (iii) Cultura Organizacional. Foram buscados principalmente livros e artigos nos idiomas Português e Inglês com relevância no estudo e com até 15 anos.

Para coletar os dados à campo foi utilizado um questionário constituído de perguntas abertas para direcionar as entrevistas semiestruturadas, presente no Apêndice A, permitindo que o entrevistado falasse livremente sobre o assunto (Gerhardt \& Souza, 2009). Nesse contexto, esta pesquisa assumiu uma abordagem qualitativa e buscou significados com base nas relações, processos e fenômenos que não podem ser explicados apenas por meio de aplicações e análises com variáveis (Minayo, Deslandes, Neto, \& Gomes, 2002).

O procedimento técnico utilizado foi o estudo de caso, o qual visa conhecer o como, o porquê da situação pesquisada e entender suas características. Como relata Gerhardt e Souza (2009), o pesquisador não deve interferir no objeto a ser estudado. Todavia, previamente a aplicação do questionário, foi feito um teste piloto (pré-teste) para aprimorá-lo com mais um entrevistado, não considerado na discussão dos resultados. Essa consideração pôde facilitar ao pesquisador a determinação de unidades de análise, reduzir o tempo de respostas e a supressão das questões redundantes ou mal formuladas (Miguel, 2007). 
A empresa em estudo é uma multinacional de grande porte fundada em 1892 que atende o mercado de energia desde sua fundação nos Estados Unidos da América. Em relação à energia renovável, já em 1918 fabricava componentes para atender hidroelétricas e mais recentemente, em 2002, iniciou a fabricação de componentes para geração eólica nos Estados Unidos. No Brasil, a fabricação de componentes para a geração de energia eólica iniciou em 2009, fornecendo diretamente para as empresas de geração de energia todos os componentes do aerogerador. Nas fábricas da empresa em estudo são realizados processos de fabricação mecânica, como usinagem por exemplo, e montagens dos componentes, sendo outros componentes do aerogerador fornecidos por empresas de sua cadeia de suprimentos. Além do fornecimento de componentes, também fornece prestação de serviços de manutenção aos parques eólicos que possuem seus aerogeradores.

As entrevistas semiestruturadas foram realizadas com responsáveis pela implementação do lean manufacturing no setor de fabricação de componentes para geração de energia renovável, visando entender os desafios à implementação, bem como quais processos e ferramentas foram utilizados. Os resultados foram comparados à conhecimentos difundidos em literaturas relacionadas ao lean manufacturing e cultura organizacional (Tabela 1).

Tabela 1. Perfil dos entrevistados está apresentado abaixo visando garantir que os profissionais tenham experiências profundas na área de estudo

\begin{tabular}{ccccccc}
\hline & Formação & Função atual & $\begin{array}{c}\text { Foco atual de } \\
\text { atuação }\end{array}$ & $\begin{array}{c}\text { Anos de } \\
\text { atuação } \\
\text { em Lean }\end{array}$ & $\begin{array}{c}\text { Anos na } \\
\text { função } \\
\text { atual }\end{array}$ & $\begin{array}{c}\text { Anos na } \\
\text { empresa } \\
\text { estudada }\end{array}$ \\
\hline $\mathbf{A}$ & $\begin{array}{c}\text { Engenharia de } \\
\text { produção }\end{array}$ & Coordenador de Lean & Fabricação & 2 anos & 2 anos & 2 anos \\
\hline B & $\begin{array}{c}\text { Engenharia de } \\
\text { produção e MBA }\end{array}$ & $\begin{array}{c}\text { Gerente sênior de } \\
\text { excelência } \\
\text { operacional }\end{array}$ & Serviços & 7 anos & 4 anos & 9 anos \\
\hline $\mathbf{C}$ & $\begin{array}{c}\text { Engenharia de } \\
\text { produção e MBA }\end{array}$ & $\begin{array}{c}\text { Gerente sênior de } \\
\text { Lean }\end{array}$ & Fabricação & 10 anos & 4 anos & 4 anos \\
\hline
\end{tabular}

As perguntas realizadas aos entrevistados foram a seguintes:

1. Quais os desafios para a implementação do "lean manufacturing" como uma cultura sustentável dentro do setor de equipamentos para geração de energia renovável?

2. Você considera a cultura organizacional um aspecto relevante a ser trabalhado durante a implementação do "lean"?

3. Quais os processos e ferramentas que foram utilizados para a implementação do "lean manufacturing" nessa indústria?

4. Como são as rotinas e atividades executadas para gestão do "lean manufacturing" no dia a dia?

Desse modo, após definir a estrutura conceitual teórica, planejar os casos, unidades de análise, descrever os casos, definir a amostra de entrevistados, conduzir o teste piloto, coletar e analisar os dados à campo, foi feita uma discussão dos resultados do estudo de caso com as implicações teóricas. 


\section{Resultados e Discussão}

A pesquisa de campo em uma organização com implementação da filosofia lean e a identificação das contribuições da literatura, embasaram os resultados práticos desta pesquisa.

As características da filosofia lean manufacturing, com atenção à cultura organizacional, e às práticas da empresa em estudo foram comparadas com à literatura para identificação de oportunidades de melhorias nos processos-chave de negócios para à empresa em estudo.

A empresa em estudo possui uma cultura de melhoria contínua bastante reconhecida principalmente decorrente dos trabalhos em Seis Sigma desde a década de 1980. Todavia, com uma recente mudança na presidência da empresa em 2018, o foco em lean foi fortalecido em comparação às décadas anteriores, havendo maior cobrança na abrangência do lean em todos os níveis da organização, com uma comunicação frequente sobre o tema, inclusive com treinamentos online sobre diversos assuntos relacionados.

Quando os entrevistados foram questionados sobre os desafios para uma implementação sustentável do lean, os temas mais comuns recaíram sobre à cultura organizacional existente no nível operacional e liderança. Os entrevistados $\mathrm{A}$ e $\mathrm{C}$ mencionaram com ênfase a não atuação da liderança na resolução de problemas e implementação, mas com cobranças de entrega de resultados no curto prazo. A Tabela 2 resume os principais pontos dos entrevistados sobre essa questão.

Tabela 2. Respostas dos entrevistados sobre os desafios para a implementação do lean manufacturing como uma cultura sustentável

\begin{tabular}{|c|c|}
\hline Entrevistado & Respostas \\
\hline $\mathbf{A}$ & $\begin{array}{l}\text { - } \quad \text { Cultura organizacional existente durante a implementação; } \\
\text { - } \quad \text { Mentalidade e comportamento dos funcionários não voltados para melhoria contínua; } \\
\text { - } \quad \text { Expectativa da liderança em entregar resultados rapidamente após a implementação. }\end{array}$ \\
\hline B & $\begin{array}{l}\text { - } \quad \text { Cultura organizacional com pessoas acostumadas com o status quo; } \\
\text { - } \quad \text { Mentalidade da liderança e falta de crença ou conhecimento sobre o lean; } \\
\text { - } \quad \text { Incômodo nas pessoas devido à implementação de processos e procedimentos. }\end{array}$ \\
\hline $\mathbf{C}$ & $\begin{array}{ll}\text { - } & \text { Liderança não atuante na implementação, apenas falas de incentivo; } \\
\text { - } & \text { Liderança não insere o lean como uma prioridade; } \\
\text { - } & \text { Não existência de uma pessoa ou time capaz de liderar a implementação. }\end{array}$ \\
\hline
\end{tabular}

Na sequência das respostas sobre os desafios da implementação do lean, os entrevistados foram questionados sobre à relevância da cultura organizacional nessa implementação e como foi o processo de implementação do lean em suas experiências nesse setor. As respostas foram unânimes sobre um desdobramento de estratégia e alinhamento de prioridades como um ponto inicial da estratégia, mencionando o hoshin kanri como uma forma visual de integrar todos os níveis da organização em uma mesma direção. As Tabelas 3 e 4 resumem os principais pontos dos entrevistados sobre essas questões. 
Tabela 3. Respostas dos entrevistados sobre a relevância e barreiras da cultura organizacional para a implementação do lean manufacturing

\begin{tabular}{|c|c|}
\hline Entrevistado & Respostas \\
\hline $\mathbf{A}$ & $\begin{array}{l}\text { - A priorização para o desenvolvimento de uma cultura lean deve iniciar no } \\
\text { desdobramento estratégico da alta liderança (Hoshin kanri) e estar presente nos valores } \\
\text { da empresa; } \\
\text { - Líderes devem acreditar verdadeiramente no lean para que a operação execute } \\
\text { consistentemente. }\end{array}$ \\
\hline B & $\begin{array}{l}\text { - O lean é uma jornada de mudança, de forma que não se cria uma organização focada } \\
\text { em melhoria contínua rapidamente; } \\
\text { - A liderança deve acreditar e comunicar constantemente sobre o lean, além de ações } \\
\text { estarem alinhadas com a filosofia; } \\
\text { - Partes interessadas e acionistas devem ter clareza que a geração de resultados através } \\
\text { da implementação do lean não é rápida. } \\
\text { - Pessoas devem ter clareza de que a responsabilidade de executar ações provenientes de } \\
\text { eventos lean não é apenas do time ou líder lean. }\end{array}$ \\
\hline C & $\begin{array}{l}\text { - A implementação será diretamente afetada de acordo com a propensão da cultura em } \\
\text { aderirem ao lean; } \\
\text { - Importante primeiro implementar em uma linha piloto para medir a adaptabilidade da } \\
\text { cultura e resistências existentes, além de mostrar mais rapidamente os resultados e } \\
\text { conquistar mais adeptos para a mudança. }\end{array}$ \\
\hline
\end{tabular}

Os respondentes explicaram como foram realizadas as implementações do lean no setor de energia renovável em uma visão de processo. Os processos mais citados na sequência de implementação foram: Desenvolvimento do hoshin kanri; Mapeamento do fluxo de valor (MFV); Eventos Kaizen. Apesar de mencionadas às etapas de treinamento das pessoas e implementação do $5 S$, fatores que segundo os entrevistados contribuem para criação de uma cultura lean de base, não foram os focos principais de suas respostas.

Tabela 4. Respostas dos entrevistados sobre o processo de implementação do lean manufacturing

\begin{tabular}{|c|c|}
\hline Entrevistado & Respostas \\
\hline $\mathbf{A}$ & $\begin{array}{l}\text { 1. Criação anual do hoshin kanri para iniciar o desenvolvimento e desdobramento da } \\
\text { estratégia, indicando o foco e os projetos que serão executados; } \\
\text { 2. Entendimento do estado atual através do MFV e alinhamento de prioridades; } \\
\text { 3. Desenvolvimento da cultura fabril pelo } 5 S \text { e treinamento em conceitos básicos da casa da } \\
\text { Toyota; } \\
\text { 4. Realização de eventos kaizen (ou } 3 P \text { ) com equipes multidisciplinares para resolução de } \\
\text { problemas apontados no MFV. }\end{array}$ \\
\hline B & $\begin{array}{l}\text { 1. Treinamento das pessoas em todos os níveis da organização e diversos setores nos } \\
\text { conceitos lean; } \\
\text { 2. Desenvolvimento da cultura através do } 5 S \text {, conceitos da casa da Toyota e programas de } \\
\text { geração de ideias; } \\
\text { 3. Criação do hoshin kanri para desenvolver e desdobrar a estratégia da organização; } \\
\text { 4. Entendimento do estado atual e interações entre áreas através de MFV multinivel; } \\
\text { 5. Realização de eventos kaizen para soluções de problemas apontados no MFV. }\end{array}$ \\
\hline $\mathbf{C}$ & $\begin{array}{l}\text { 1. Análise da cultura da organização e dos conhecimentos de lean das pessoas. } \\
\text { Mapeamento das habilidades existentes e engajamento da liderança através de } \\
\text { entrevistas formais ou informais; } \\
\text { 2. Alinhamento dos principais indicadores estratégicos a serem melhorados (hoshin kanri); } \\
\text { 3. Realização do MFV estado atual e estado futuro, revisando no mínimo anualmente; } \\
\text { 4. Execução de eventos kaizen com base nos gargalos encontradas no MFV. }\end{array}$ \\
\hline
\end{tabular}

Segundo os respondentes, uma vez realizada a primeira rodada de implementação do lean, a sequência se daria com eventos kaizen com focos em outros desperdícios ou gargalos do 
processo, ou mesmo por meio do MFV em uma nova área. Dessa forma, para a gestão de acompanhamento foram utilizados o próprio hoshin kanri com os indicadores inseridos, bem como utilizando alguma ferramenta de resolução de problemas e análise de causa raiz para atacar problemas pontuais (Tabela 5).

Tabela 5. Respostas dos entrevistados sobre a rotina de gestão do lean

\begin{tabular}{|c|c|}
\hline Entrevistado & Respostas \\
\hline $\mathbf{A}$ & $\begin{array}{l}\text { - Utilização de metodologias de resolução de problemas (diagrama de espinha de peixe) } \\
\text { para problemas encontrados no dia a dia; } \\
\text { - } \quad \text { Monitoramento dos indicadores padrões para produção e projetos; } \\
\text { - Visitas diárias ao Genba pela liderança; } \\
\text { - } \\
\text { Relatórios gerenciais para lideres seniores da organização sobre ações e indicadores } \\
\text { (hoshin kanri). }\end{array}$ \\
\hline B & $\begin{array}{l}\text { - Reuniões mensais com os gestores dos projetos para atualização do hoshin kanri; } \\
\text { - Acompanhamento da liderança sobre os indicadores relacionados ao hoshin kanri; } \\
\text { - Execução de análise de causa raiz e plano de reação para indicadores abaixo do } \\
\text { esperado. }\end{array}$ \\
\hline C & $\begin{array}{l}\text { - Reuniões com a liderança para atualização dos principais indicadores estratégicos } \\
\text { (hoshin kanri); } \\
\text { - Reuniões com o time executor para alinhamento e atualização das ações; } \\
\text { - Rondas diárias pelas áreas e quadros de gestão visual; } \\
\text { - Execução de análise de causas raízes e/ou eventos kaizen para melhorar pontos } \\
\text { - específicos; } \\
\text { - Divulgação de jornais kaizen das melhorias conquistadas para toda a planta. }\end{array}$ \\
\hline
\end{tabular}

Ainda que os entrevistados atuem em diferentes áreas e unidades da empresa no setor estudado, foi entendido que a maioria dos processos são comuns, uma vez que há uma padronização da estratégia lean. Baseado nas respostas obtidas, os processos que governam a implementação em linhas gerais são: Planejamento hoshin kanri, o Mapeamento do Fluxo de Valor (MFV) e os eventos kaizen. Esses três serão estudados e comparados com à literatura existente nos tópicos seguintes.

\subsection{Planejamento hoshin kanri}

O ponto de partida para a implementação do lean de acordo com todos os entrevistados se deu por meio do hoshin kanri utilizando o padrão visual da Matriz X, exemplificada na Figura 1. Conforme explicado pelos entrevistados, nesse padrão são colocados os objetivos do ano alinhados com os objetivos de longo prazo, elencando as ações prioritárias e os indicadores que devem ser impactados. Esses objetivos identificados pela alta liderança são cascateados para outros níveis da organização com objetivos mais específicos, garantindo que todos trabalhem na mesma direção. Os entrevistados $\mathrm{B}$ e $\mathrm{C}$ mencionaram que as revisões junto à liderança são mensais, na qual indicadores e objetivos são monitorados e revisados. Da mesma forma, as ações desdobradas são revisitadas com os times responsáveis semanalmente.

De acordo com o entrevistado A, a cultura lean da companhia deve nascer junto com o desdobramento estratégico na alta liderança, bem como nos valores que a empresa emprega. $\mathrm{O}$ entrevistado $\mathrm{B}$ também menciona que a implementação do lean é uma jornada de longo prazo e que a alta liderança deve acreditar verdadeiramente, para que seja criada essa cultura sustentável. Comparativamente à literatura sobre o STP, Liker (2005) comenta que o primeiro passo para seguir o caminho da Toyota é a aplicação de uma filosofia de objetivos de longo 
prazo de forma que os objetivos de curto prazo possam seguir essa direção. Womack e Jones (2003) mencionam que o passo um para o pensamento lean é a criação de valor ao cliente, sendo que as prioridades devem estar alinhadas com o requisitado pelos clientes, não pelos acionistas ou gestores. No longo prazo, o que deixar o cliente satisfeito, também será para os acionistas e gestores.

Figura 1. Matrix X para desdobramento de estratégia usando o Planejamento Hoshin adaptado de LaHote, 2015.

\begin{tabular}{|c|c|c|c|c|}
\hline$X$ & & Revisar planos e metas dos funcionários & $X$ & \\
\hline & X & Criação de linhas dedicadas & & $X$ \\
\hline \multirow[t]{2}{*}{ 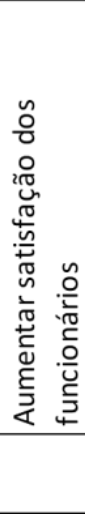 } & 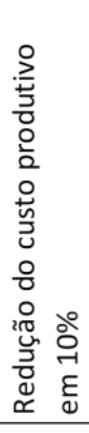 & Objetivos de longo & 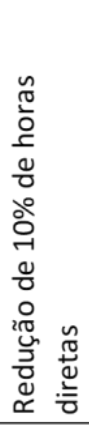 & 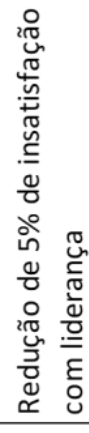 \\
\hline & $X$ & Aumentar lucros em $15 \%$ & & $X$ \\
\hline$X$ & & Mudança cultural com base no "Lean" & $X$ & \\
\hline
\end{tabular}

Liker e Convis (2013) mencionam que na Toyota a liderança é inteiramente centrada na busca do norte verdadeiro e o hoshin kanri é o mais poderoso processo da Toyota para alinhar todos os indivíduos ao longo das diversas divisões da companhia. Se as pessoas em cada nível perguntassem quais são seus problemas baseados na condição atual e no objetivo, de forma a pensar nas causas raízes desses problemas, então às pessoas em diferentes níveis desenvolveriam planos diferentes, mas alinhados aos objetivos comuns da organização. Os autores acrescentam que em organizações que existem relacionamentos falhos na liderança ou empresas que recorrem a demissões dos líderes em períodos de baixas, necessitam sempre recomeçar do zero em relação ao desenvolvimento das pessoas até atingir o alinhamento desejado.

De acordo com Dennis (2008), o planejamento hoshin é o sistema nervoso da produção lean, sendo que com frequência as implementações do lean falham devido a inabilidade das organizações e pessoas em focar. Nesse processo, é realizado um planejamento de curto prazo (um ano) e de longo prazo (três a cinco anos) para alinhar à estratégia e resolver as questões mais cruciais da empresa, deixando pessoas e ações na mesma direção. Segundo Dennis (2008), existem quatro etapas no planejamento hoshin: o desenvolvimento, a disposição, a implementação e a revisão. Dentro desse processo de desdobramento, é feito o que Liker e Convis (2013) chamam de catch-ball (jargão esportivo que significa bate bola), com o refinamento dos objetivos nos setores abaixo, sendo que durante as revisões são validados os objetivos do hoshin em relação à viabilidade e alocação de recursos. 

de geração de energia: uma análise comparativa entre a teoria e a prática. Brazilian Journal of Production Engineering, 8(1), 18-32.

Figura 2. Desdobramento do planejamento hoshin adaptado de Liker e Convis (2013).

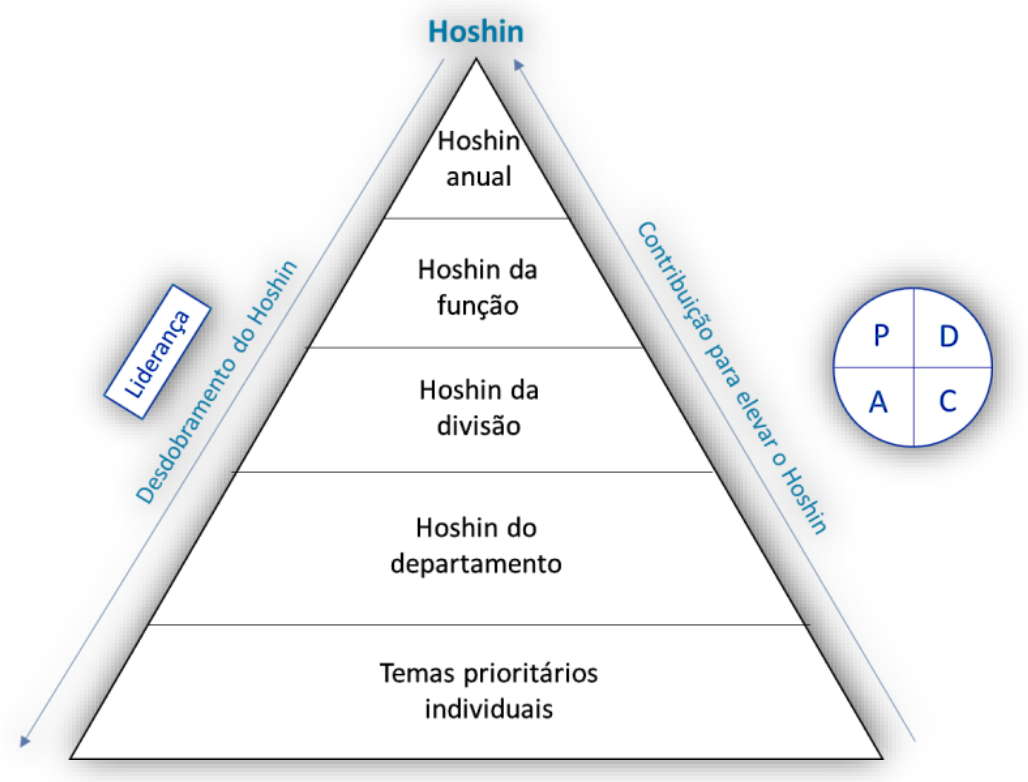

Liker e Convis (2013) afirmam que no STP não existe a Matriz X, sendo esse apenas um método criado por consultorias. Na Toyota, o hoshin é uma ferramenta de colaboração e desenvolvimento de pessoas por meio da solução de problemas. Essa relação entre os objetivos não é atingida por uma matriz, mas por meio de discussões verticais (líder e equipe) e horizontais (entre funcionários). A matriz X poderia ser usada para examinar pontos específicos, mas dificilmente mediria a estrutura e a cultura da organização. Nesse sentido, o sistema de gestão diária é a ferramenta principal para sustentar o hoshin, visando conferir os resultados reais em relação aos resultados pretendidos e envolver a equipe na solução criativa de problemas. A meta é tanto desenvolver pessoas quanto atingir resultados.

Os entrevistados A e C mencionaram que a caminhada pelo chão de fábrica para verificação de indicadores, bem como utilização de metodologias de resolução de problemas para falhas identificadas nessas rondas são processos comuns em suas rotinas. Foi entendido pelas respostas que as revisões mensais do hoshin têm bastante importância para a liderança na verificação do andamento de indicadores e ações em relação ao cumprimento dos objetivos esperados, indicando uma oportunidade de melhoria para maior relacionamento com as rotinas de gestão diárias.

Em linhas gerais, foi identificado uma grande similaridade no objetivo do emprego do hoshin kanri na empresa do setor estudado em comparação ao mencionado na literatura clássica do STP. O ponto de maior divergência entre os autores e à empresa estudada está na utilização da Matriz X para criar uma proposta visual elencando todas os objetivos de curto e longo prazo, bem como as ações, indicadores e responsáveis. Essa divergência não é entendida como um prejuízo na aplicação do hoshin kanri desde que seu desenvolvimento se desdobre para todos os níveis da organização, de forma a criar uma cultura que envolva todos na mesma direção, Liker e Convis (2013). Do contrário, a Matriz X seria apenas uma ferramenta estática de medição de resultados com base nos indicadores, envolvendo apenas à liderança e excluindo o restante da empresa. 


\subsection{Mapeamento do Fluxo de Valor (MFV)}

$\mathrm{O}$ mapeamento do fluxo de valor (MFV) foi apontado pelos entrevistados A e C como segundo passo para a implementação do lean e explicado que, por meio do alinhamento estratégico do hoshin kanri, o MFV é realizado em linhas de produção com impacto direto nos objetivos definidos a fim de identificar gargalos nos fluxos de materiais e/ou informações para que sejam solucionados posteriormente. $\mathrm{O}$ entrevistado $\mathrm{C}$ explicou que durante uma implementação é selecionada uma linha de produção ou área, chamada de modelo, a qual será a vitrine para toda a companhia do impacto da cultura lean.

O entrevistado B relatou que geralmente é desenvolvido o MFV em diversos níveis de detalhes: Primeiramente em um nível maior com visualização do fluxo de material e informação da planta toda; Em seguida o processo identificado como gargalo é estudado através de outro MFV e; finalmente um MFV de terceiro nível para maior detalhamento do processo que gera o maior gargalo.

Apesar de diferentes abordagens pelos três entrevistados quanto à seleção de onde deve ser estudado utilizando o MFV, o objetivo é similar, resolver problemas que mais impactam na criação de um fluxo contínuo e tempo de resposta (lead time). Os três entrevistados mencionaram que o MFV do estado futuro é desenvolvido com base nos objetivos préestabelecidos, sendo o MFV do estado corrente atualizado ao menos anualmente. Além disso, são realizados novos MFV conforme gargalos são resolvidos, esta recorrência faz com que o ciclo PDCA gire.

Womack (2003) ao enumerar o pensamento do STP em passos insere logo após a identificação das necessidades do cliente, a descoberta do fluxo de valor em segundo lugar e a criação de fluxo em terceiro. Na mesma direção, Liker (2005) adiciona a criação de um fluxo contínuo como o segundo passo dentre os 14 princípios do modelo Toyota, logo após o desenvolvimento da jornada de longo prazo, para a implementação de uma cultura como a do STP, como pode ser visto na Figura 3. Desta forma, o objetivo é trazer à tona logo no início as dificuldades que impedem a criação do fluxo de uma peça, no qual é possível tornar visível ineficiências ao parar à linha de produção.

Figura 3. Os 14 princípios do modelo Toyota adaptado de Liker (2005).

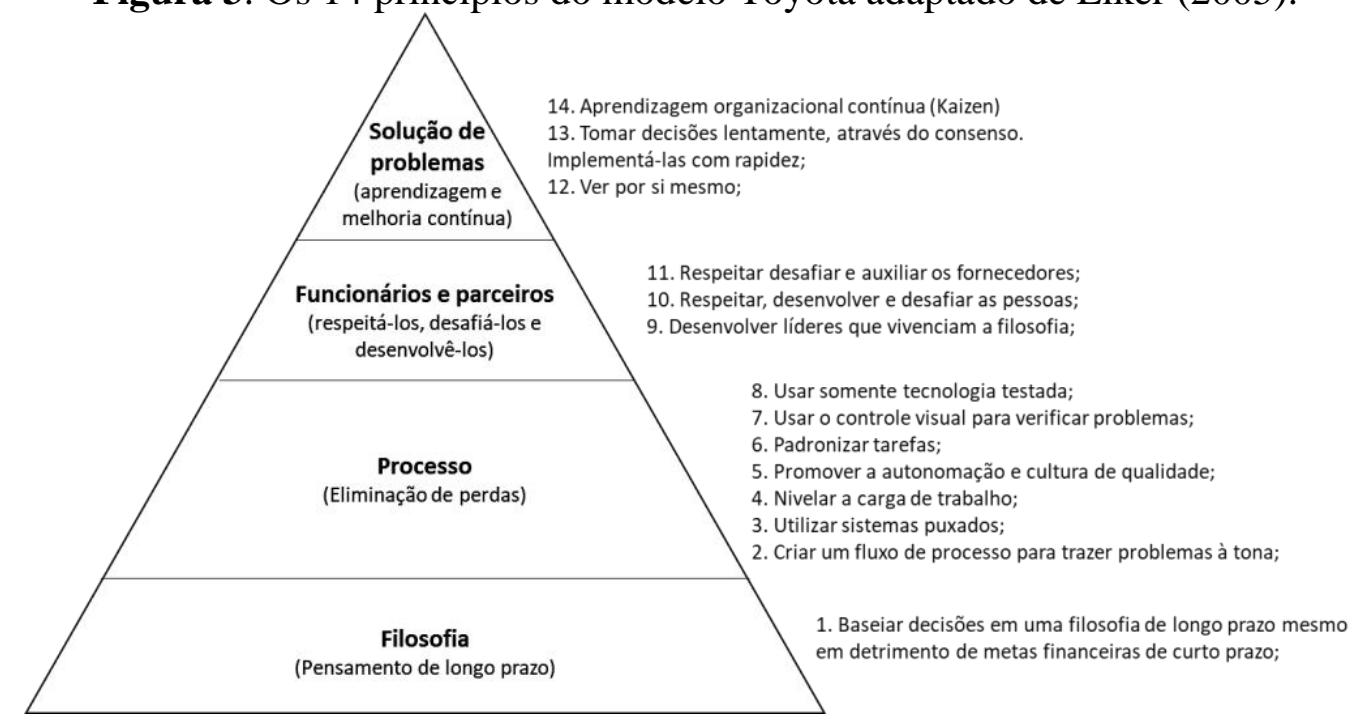



de geração de energia: uma análise comparativa entre a teoria e a prática. Brazilian Journal of Production Engineering, 8(1), 18-32.

Rother e Shook (2013) explicam que o MFV é uma ferramenta essencial para visualizar mais que um processo único, ajudando a identificar mais do que desperdícios, mas as fontes dos desperdícios. É a base para um plano de implementação, ajudando a desenhar como um fluxo porta a porta deveria operar, como se fosse um mapa para iniciar a implementação do lean. $\mathrm{O}$ estado futuro é um plano que deve conter os requerimentos do cliente e os conceitos lean como o sistema puxado, estoque nivelado e sistemas de abastecimento, entretanto a implementação do plano de ação deve ser segmentada de forma que existam loops que serão resolvidos em diversas rodadas.

O estado futuro mostra onde se quer chegar e deve ser revisado anualmente para a criação do passo a passo da implementação com metas atingíveis. Normalmente é seguindo a seguinte ordem de resolução de problemas: Desenvolver um fluxo contínuo baseado no ritmo (takt) requerido; estabelecer um sistema puxado para controlar a produção; introduzir o nivelamento de produção; praticar kaizen para continuar eliminando desperdícios (Rother \& Shook, 2013).

Com base na literatura e nas respostas dos entrevistados, ambos fazem uso do MFV logo após a definição dos objetivos estratégicos, como se fosse uma foto do estado atual e um plano de onde se quer chegar. Além disso, é possível identificar uma diferença no desenvolvimento do MFV, como o desdobramento em diversas camadas, como mencionado pelo respondente B, de forma a integrar todos os níveis e identificar em níveis mais granulares onde está o problema. Estas singularidades foram bem explicadas pelos entrevistados uma vez que atuam em diferentes áreas e contextos diferentes, dando uma maior ênfase no fluxo de materiais e outros no fluxo de informação. Este último é bem pouco comentado pelos autores citados, apesar de Rother e Shook (2013) mencionarem a importância de que o grupo de promoção lean suporte todas as funções do negócio, não apenas a manufatura.

Em um contexto mais geral, existe um alinhamento na visão e estrutura do MFV em relação aos objetivos organizacionais e uma forma de iniciar a operacionalização da mudança desejada. Como mencionado por Rother e Shook (2013), o MFV é uma oportunidade de mudança da organização focada em departamentos para times de produtos, gerando um engajamento e fazendo as pessoas verificarem os problemas no local.

\subsection{Eventos kaizen}

Todos os entrevistados mencionaram de alguma forma que o passo seguinte à criação do MFV é a execução de um ou mais eventos kaizen para resolver gargalos encontrados no estado atual em direção ao estado futuro. De acordo com as respostas, os eventos são realizados normalmente de 3 a 5 dias com um time multidisciplinar para eliminação dos sete desperdícios e implementação de conceitos como puxada de produção, padronização, gestão visual e abastecimento de materiais. Este último ponto foi um dos mais frisados pelo entrevistado A, mencionando como um processo recorrente de necessidade de melhoria junto ao time de Gestão de Materiais para atendimento às linhas de produção, bem como para redução de inventário de matéria prima.

Foi mencionado também eventos $3 P$ principalmente para mudanças grandes no layout e ritmo de produção. Neste contexto, será incluído este tipo de evento à um kaizen mais específico.

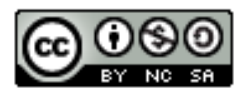



de geração de energia: uma análise comparativa entre a teoria e a prática. Brazilian Journal of Production Engineering, 8(1), 18-32.

Outras ferramentas mencionadas menos vezes, como o $5 S$, não serão parte desta análise para focar em processos comuns aos entrevistados.

Em comparação aos 14 princípios do modelo Toyota de Liker (2005) e baseado nas respostas dos entrevistados, os eventos kaizen são responsáveis pela implementação de processos das etapas 3 a 8, conforme Figura 3. Além dos resultados esperados dos eventos kaizen para atingimento do estado futuro, o entrevistado A explicou que possuem também a função de treinamento prático dos conceitos fornecidos previamente às pessoas, tendo uma função de desenvolvimento de pessoas e cultura.

Liker (2005) têm uma visão bastante similar, ao explicar que os eventos kaizen de uma semana inteira se constituem em experiências de aprendizado. $\mathrm{O}$ autor explica que após centenas de experiências de eventos kaizen, o indivíduo passa por uma transformação pessoal e começa a compreender com mais profundidade o quanto a aplicação das ferramentas e princípios levam às melhorias. Sobre a cultura, o autor explica que o desenvolvimento de uma equipe de indivíduos com grande nível de experiências pessoais guia o caminho para a autossustentação da melhoria continua, de forma que estes estejam certos de que sabem como realizar a melhoria e que nunca permitirão seguir o caminho contrário.

Um ponto que Liker e Convis (2013) apresentam é sobre a atribuição da palavra kaizen ao sentido de montar uma equipe especial para um projeto utilizando métodos lean ou organizando um evento de uma semana. Segundo os autores, essa atribuição faz parecer que o kaizen é uma atividade isolada e realizada uma única vez, entretanto na Toyota o kaizen não são apenas eventos especiais, mas parte integrante da liderança ao apoiar o kaizen diário. No geral, as empresas sentem que os ganhos de projetos lean são muito difíceis de serem mantidos, e com o kaizen diário não seria diferente, necessitando de energia das pessoas e da liderança para fazê-los acontecer.

Segundo os entrevistados, o suporte da liderança para que os eventos kaizen de 5 dias aconteçam é um grande esforço, ainda mais com a presença destes líderes. O mesmo ponto se aplica à gestão de rotinas ou kaizen diários, onde o nível de engajamento da liderança é um fator crucial e bastante difícil de conseguir. Sendo assim, essa seria uma lacuna a ser vencida em relação à cultura lean em direção à sustentabilidade.

Ainda em relação aos exemplos dados pelos entrevistados, foi entendido que os eventos de 5 dias são executados normalmente uma vez ao mês para endereçar problemas específicos advindos do MFV. O entrevistado B foi o único a mencionar a iniciativa de geração de ideias como forma de ampliar a compreensão de kaizen e passar a praticar de forma recorrente com blocos ou objetivos menores, se aproximando da ideia de kaizen diário.

Desta forma, foi identificado uma diferença no processo de kaizen executado pela empresa em estudo em relação à literatura da Toyota sobre à aplicação diária. A empresa em estudo se mostrou mais focada, com base nas respostas, em eventos isolados de 3 a 5 dias para resolução de problemas e, por outro lado, realiza apenas rondas diárias de acompanhamento dos indicadores. Além disso, a participação da liderança nos eventos foi um ponto bastante frisado nas respostas, sendo um fator importante para o desenvolvimento da cultura lean na empresa de forma sustentável. 


\section{Conclusão}

O objetivo foi o estudo de caso da implementação da filosofia lean manufacturing no setor de fabricação de componentes para geração de energia renovável, a fim de comparar os desafios da implementação e os processos executados com a literatura clássica sobre o assunto. A pesquisa abrangeu três entrevistados do mesmo setor, entretanto com atuações em diferentes áreas, desta forma foi perceptível a integração da estratégia e processos implementados, sendo os três processos centrais na sequência de implementação: o planejamento hoshin, o Mapeamento do fluxo de valor e os eventos kaizen. Este conceito simplificado está bastante alinhado principalmente com os 14 princípios do modelo Toyota de Liker (2005). De acordo com o estudo, o planejamento hoshin foi implementado com grande similaridade à literatura, divergindo apenas na utilização de uma matriz visual pela empresa em estudo. $O$ mapeamento do fluxo também apresentou uma grande similaridade, apesar de alguns entrevistados utilizarem diferentes níveis de mapeamento para identificar os gargalos a serem solucionados. Por fim, o evento kaizen foi o processo que apresentou maior divergência com a literatura, mas alinhamento com as respostas relacionadas à cultura organizacional. A inexistência de um kaizen diário na empresa em estudo é entendido como um fator crítico pela literatura para engajamento da liderança e sustentabilidade da cultura lean. Desta forma, foi entendido que a implementação da filosofia lean manufacturing no setor de fabricação de componentes para geração de energia renovável segue um modelo bastante similar ao existente na literatura baseada na indústria automotiva e as adaptações não são originais à indústria de energia renovável, mas uma integração de pequenos outros conceitos de outras literaturas, não alterando a forma macro do processo da literatura comparada. Os pontos de melhoria elencados no estudo sugerem uma integração ainda maior com a literatura já seguida pela indústria renovável, sendo a liderança o fator principal a ser trabalho para uma difusão maior da filosofia no ambiente produtivo da empresa estudada. $\mathrm{O}$ treinamento desta liderança com o pensamento participativo na resolução de problemas e foco no longo prazo pode prevenir a sustentabilidade da jornada de implementação da filosofia lean esteja em risco.

\section{Referências}

Callefi, J. \& Crubellate, J. M. (2020). O Sistema Toyota de Produção: institucionalismo comunicativo e a cultura organizacional. Revista Gestão \& Tecnologia. 20(1), 209-229. https://doi.org/10.20397/2177-6652/2020.v20i1.1599

Dennis, P. (2008). Produção Lean Simplificada: Um guia para entender o sistema de produção mais poderoso do mundo (2a ed). Porto Alegre: Bookman.

Fachin, O. (2006). Fundamentos de metodologia (5a ed). São Paulo: Saraiva.

Gabriel, M.L. (2014). Métodos Quantitativos em Ciências Sociais: Sugestões para Elaboração do Relatório de Pesquisa. Desenvolvimento Em Questão, 12(28), 348-369. https://doi.org/10.21527/2237-6453.2014.28.348-369

Gerhardt, T. E. \& Souza, A. C. (2009). Métodos de Pesquisa (pp. 11-25) (1a ed). Porto Alegre: Editora da UFRGS.

Gil, A. C. (2002). Como elaborar projetos de pesquisa (4a ed). São Paulo: Atlas. 

de geração de energia: uma análise comparativa entre a teoria e a prática. Brazilian Journal of Production Engineering, 8(1), 18-32.

Gross, J. M. \& McInnis, K. R. (2003). Kanban Made Simple: Demystifying and Applying Toyota's Legendary Manufacturing Process (1a ed). Nova Iorque: AMACOM.

Koenigsaecker, G. (2011). Liderando a transformação Lean nas empresas (1a ed). Porto Alegre: Bookman.

LaHote, D. (2015). What strategy is and what it's not. Lean Institute Brasil. Recuperado de https://www.lean.org/leanpost/Posting.cfm?LeanPostId=357

Liker, J.K. (2005). O Modelo Toyota: 14 princípios de gestão do maior fabricante do mundo. (1a ed). Porto Alegre: Bookman.

Liker, J. K. \& Convis, G. L (2013). O modelo Toyota de liderança Lean: Como conquistar e manter a excelência pelo desenvolvimento de lideranças (1a ed). Porto Alegre: Bookman.

Miguel, P. A. C. (2007). Estudo de caso na engenharia de produção: estruturação e recomendações para sua condução. Production. 17(1), 216-229. https://doi.org/10.1590/S0103-65132007000100015

Minayo, M. C. de S., Deslandes, S. F., Neto, O. C., \& Gomes, R. (2002). Pesquisa social: Teoria, método e criatividade (21a ed). Petrópolis: Vozes.

Paro, P. E. P. (2016). Sistemática de transformação: desenvolvimento teórico para o alinhamento entre estratégia e cultura organizacional nos projetos de Lean (Dissertação de Mestrado). Universidade de São Paulo, São Carlos, SP, Brasil. Recuperado de https://www.teses.usp.br/teses/disponiveis/18/18156/tde-05072016-102816/pt-br.php

Pires, J. C. S. \& Macedo, K. B. (2006). Cultura organizacional em organizações públicas no Brasil. RAP, 40(1), 81-105. https://doi.org/10.1590/S0034-76122006000100005

Raupp, F. M. \& Beuren, I. M. (2008). Como elaborar trabalhos monográficos em Contabilidade. (pp. 76-97). (3a ed). São Paulo: Atlas.

Rother, M. (2010). Toyota Kata: Gerenciando pessoas para melhoria, adaptabilidade e resultados excepcionais (1a ed). Porto Alegre: Bookman.

Rother, M. \& Shook, J. (2013). Aprendendo a enxergar: Mapeando o fluxo de valor para agregar valor e eliminar o desperdício (1a ed). São Paulo: Lean Institute Brasil.

Schein, E. H. (1984) Coming to a new awareness of organizational culture. MIT, Sloan Management Review. Recuperado de https://sloanreview.mit.edu/article/coming-to-a-newawareness-of-organizational-culture

Werkema, C. (2003). Criando uma cultura Lean Seis Sigma (3a ed). Rio de Janeiro: Elsevier.

Womack, J. P. \& Jones, D. T. (2003). Lean Thinking: Banish waste and create wealth in your Corporation. ( $2 \mathrm{a}$ ed). Nova Iorque: Free Press.

Zanella, L. C. H. (2011). Metodologia de Pesquisa (2a ed). Departamento de Ciências da Administração, Universidade Federal de Santa Catarina, Florianópolis, SC, Brasil. Recuperado de http://arquivos.eadadm.ufsc.br/EaDADM/UAB_2014_2/Modulo_1/Metodologia/material_did atico/Livro\%20texto\%20Metodologia\%20da\%20Pesquisa.pdf 